\title{
Temporomandibular Disorders and Orthodontic Treatment - A Review with a Reported Clinical Case
}

\author{
Tomislav Badel ${ }^{1}$, Miljenko Marotti ${ }^{2}$ and Ivana Savić Pavičin ${ }^{3}$ \\ ${ }^{1}$ Department of Prosthodontics, \\ School of Dental Medicine, University of Zagreb \\ ${ }^{2}$ Department of Diagnostic and Interventional Radiology, \\ "Sestre Milosrdnice" University Hospital Center, University of Zagreb \\ ${ }^{3}$ Department of Dental Anthropology, School of \\ Dental Medicine, University of Zagreb \\ Croatia
}

\section{Introduction}

Temporomandibular disorders (TMDs) are musculoskeletal disorders affecting the temporomandibular joint (TMJ), the masticatory muscles (myogenic subgroup), or both, and they are the most common cause of orofacial somatic nonodontogenic pain. Osteoarthritis (OA) and disc displacement (DD) of TMJ belong to the arthrogenic subgroup of TMDs (Okeson \& de Leeuw, 2011).

The aim of the paper is to evaluate the relationship between malocclusion, orthodontic treatment and development of TMD. The article includes a 5-year follow-up of a female patient who underwent orthodontic treatment instead of TMD treatment.

\section{Diagnostics of painful TMDs}

The multifactorial etiopathogenic models of TMDs have no practical use at patient level because certain occlusal conditions, exposure to psychological macrotrauma, bruxist behaviour, etc., cannot be associated with TMD symptoms which are exhibited by the patient. Idiopathic (nonspecific) etiology imposes a personalised approach to every single patient during diagnostics, planning and the use of treatment modalities as well as during recall. TMD symptomatology includes the main symptoms such as pain of masticatory muscles and/or TMJ, limited and painful mouth opening as well as pathologic noise in the joints. Pain is the most important symptom in TMDs pathogenesis due to which patients seek treatment and therefore, the main aim of the treatment is pain removal (Jürgens, 2009).

The biopsychosocial component is strongly based on chronification of musculoskeletal pain. The biopsychosocial concept includes a combination of biological and psychological considerations on the etiology of TMDs, particularly those accompanied by chronic pain. Chronic pain has its etiologic basis in somatosensory and psychosocial factors. Patients with 
chronic pain live with their biological problem (pain activation with or without obvious pathology), which can have a psychological foundation as well as effects on their behaviour. Specific social (interpersonal) relations often have negative effects for patients (Türp, 2000; Giannakopoulos et al., 2010).

The most widespread system of standardised examination of patients and asymptomatic individuals is the use of RDC (Research diagnostic criteria)/TMD, which includes a clinical examination in Axis I, and a psychiatric testing in Axis II (Dworkin \& Le Resche, 1992). RDC/TMD system classifies TMDs into three subclasses: muscle disorders, DD, and arthralgia/arthritis/arthropathy. The importance of such a system is that it shows a possibility of defining certain diagnoses of TMDs wherein the diagnosis of one subgroup does not exclude the diagnosis from the other subgroup in the same patient. Nevertheless, there are certain limitations because RDC/TMD does not include a supplementary magnetic resonance imaging (MRI) diagnostics.

\subsection{Manual functional analysis}

Bumann in collaboration with Groot Landeweer provided an overall system to diagnose TMDs, and, together with Lotzmann, confirmed it by thorough MRI diagnostics of TMJ (Bumann \& Lotzmann, 2002). The use of manual functional analysis (MFA) is particularly stressed in the evaluation of the condition of the stomatognathic system prior to major irreversible procedures in order to avoid delayed detection of more or less pronounced clinical signs and symptoms of TMDs which would not be recognized and treated on time in such a case (Figure 1). MFA is a result of collaboration between the orthodontist and physiotherapist and its first purpose was to perform screenings prior to orthodontic treatment (Bumann \& Lotzmann, 2002). By including MRI along with prior use of MFA, the less known diagnoses can be established such as partial DD and DD upon excursive movement of TMJ (Badel et al., 2009a).
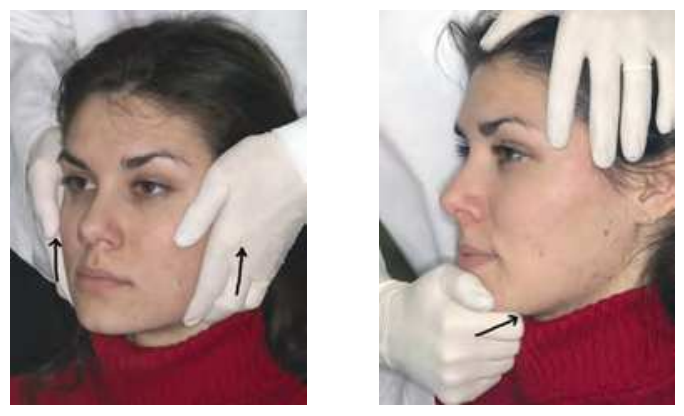

Fig. 1. Dynamic compression starts with the therapist cranially pressuring the distal edge of the mandibular corpus (left), and dorsal passive compression (right).

The main purpose of clinical diagnostics is to determine the pathological condition of masticatory muscles and/or the TMJs. A standard dental examination focusing on dental status and occlusion is insufficient for diagnostics as well as just measuring the mouth opening (Kropmans et al., 2000). Manual diagnostic methods of the stomatognathic system are necessary for (von Piekartz, 2005): 
- differential diagnostics of muscular, arthrogenic disorder or both;

- determining the status of the articular disc and the articular surfaces;

- measuring the passive capacity of mouth opening, and

- making specific diagnoses.

\subsection{Clinical importance of imaging modalities}

A limiting factor in the study of TMDs is radiologic diagnostics, which is often used in dental treatment of teeth and jaw bones. Traditional x-ray images as well as conventional and computed tomography (CT) cannot show all the functional elements of TMJ. The key component in articular biomechanics is the relationship between the articular plate or disc as a cartilaginous structure and the condylar head as an osseous structure. Another factor is the disc-condyle complex relationship with the posterior plane of the articular eminence, across which the articular complex moves simultaneously on mouth opening.

Ahmad et al. (2009) believe that panoramic x-ray and TMJ radiography should not be included into diagnostic procedure at the specialist level. CT is indicated in individuals who have clinical signs of $\mathrm{OA}$ and who cannot be exposed to strong magnetic field due to claustrophobia, metal implants or pacemakers. In individuals with such limitations, CT would not be an adequate diagnostic means if they only have DD without any changes in hard osseous tissues. When the MRI finding of OA needs to be confirmed by CT, which is still the gold standard in diagnostics of osseous tissues of joints (Figure 2), one should bear in mind the exposure to $x$-ray radiation. MRI is a radiologic technique of layered imaging in the desired plane without moving the body and without exposing the patient to ionised radiation. As in the other fields of diagnostics in medicine, MRI is qualitatively better because it enables imaging of soft tissues without invasive effects on the recorded object as opposed to arthrography. Therefore, MRI has become the gold standard of diagnostics and the dominant radiologic technique in diagnostics of TMDs enabling the imaging of cartilaginous articular surfaces and it can successfully show the position of the articular disc (Badel et al., 2009a; Badel et al., 2010a).
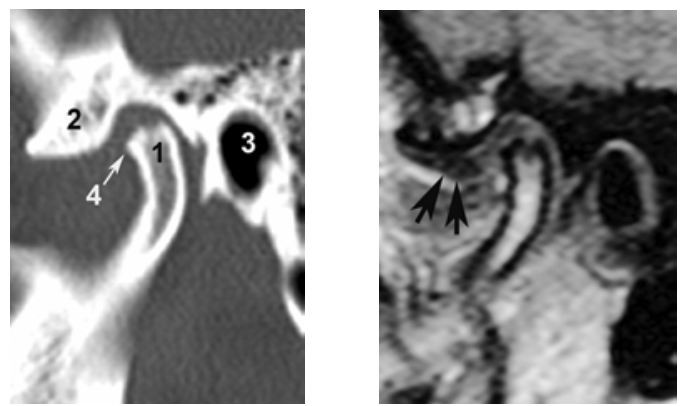

Fig. 2. Computed tomography (left) of temporomandibular joint with degenerative bone changes (1 condyle, 2 articular eminence, 3 external acoustical meatus, 4 osteophyte) and magnetic resonance imaging (right) with anterior displaced disc (arrow).

In orthopedics, the possibilities of manual tests and limitations of traditional radiologic examinations as well as advantages of MRI have already been evaluated. The relationship 
between pain and diagnostic findings has also been researched, particularly the relationship between the knee and the lumbar region of the spine. Regarding clinical diagnostics, Palla (1998) concluded that certain forms of TMDs do not have specific signs, that is, certain diagnostic tests have low validity and reliability.

\section{Epidemiology of TMD and the use of MRI}

A high prevalence of symptoms, 25-75\%, out of which the major part of the symptoms were pathological noise in the TMJ, was determined in general population by various methods of data gathering (questionnaires, clinical examination, use of radiologic modalities). Although there are some methodological discrepancies which can be hinder the direct comparison of epidemiologic results of TMD, it is certain that temporomandibular pain has a low prevalence, mostly less than $10 \%$ of general population, and most often only $5 \%$ (Durham, 2008). In an epidemiologic study, Gesch et al. (2004a) determined by a clinical examination of $49.9 \%$ of the population that there is at least one clinical sign of TMD, whereas only $2.7 \%$ had painful TMJ.

Another issue in the TMD epidemiology is dependence on the age and gender of the patient. Manfredini et al. (2010) differentiated two age peaks (two peaks of greatest incidence) in TMD patients (30-35 and 50-55 years) with female: male ration 5:1, which partly coincides with previous knowledge that the greatest prevalence is in women of reproductive age (that is between 18-45) (Palla, 1998; Badel, 2007a; Durham, 2008). Although osteoarthritis has only partly greater prevalence in elderly people, it is obvious that TMDs do not progress with patients' age. Using MRI, Schmitter et al. (2010) proved that in elderly population, each gender equally, there is a discrepancy of high incidence (70\%) of OA signs accompanied by low incidence of clinical signs of TMD (out of 30 subjects only one had painful TMJ). Predominance of females in TMD patients is explained by the effects of female hormones or attribute this to the gender distinction, biological and physiological differences, behavioural characteristics, and genetic factors (Wang et al., 2008).

In order to plan and perform orthodontic treatment, it is important to have all the data regarding TMD symptoms as well as the need to treat them in the population of children and adolescents during the period of growth and the development of jaws and teeth. The issue of orthodontics is related to data gathered within epidemiologic studies of young people. In this way, in a group of adolescents and young adults, Casanova-Rosado et al. (2006) found that $16.55 \%$ of them had orthodontic treatment. Some grade of TMD was found by clinical examination in $46.1 \%$ of subjects, predominantly females with bruxist behaviour and psychosocial variables (stress and anxiety). However, it is not evident to what extent were the subjects treated orthodontically. Le Resche et al. (2005) pointed to the higher prevalence of pain, including TMD pain (in terms of multiple pain problems) during pubescent development of girls. Pereira et al. (2009) found at least one sign or symptom of TMD in $12.26 \%$ of children aged between $4-12$ (in 5 boys and 8 girls). Bonjardim et al. (2003) determined a low prevalence of TMD signs and symptoms in children aged between 3 and 5 (primary dentition): $3.03 \%$ had TMJ sounds and $4.04 \%$ had jaw pain without any gender differences. Köhler et al. (2009) followed the occurrence of signs and symptoms of TMD during 20 years, with the first examination at the age of three. It was determined that TMD symptoms had higher incidence in later examinations (incidence 5-9\%) while at the youngest age, there was almost none. However, the need for treatment is particularly low 
(1-2\%). Huddleston Slater et al. (2007) did a targeted research into prevalence of anterior DD with reduction (accompanied by reciprocal clicking in the TMJ) in children and adolescents which increases with their age, yet there is no statistical difference in prevalence between a subgroup of 18-year-old adolescents and two age groups of adults aged on average 21.9 and 43.5. Prevalence of DD with reduction je rose to $26.6 \%$ in adulthood.

MRI diagnostics of a 12-year-old female patient with clinical signs and symptoms of clicking in both jaws was performed as a part of pre-orthodontic treatment. The MRI finding confirmed DD with reduction in the left and without reduction in the right TMJ. The MRI follow-up finding remained unchanged after the treatment of unilateral cross bite. Painless clicking as a compensated condition of TMJ was not sufficient as a symptom which would indicate TMD treatment (Badel et al., 2008a).

In a sample of 40 patients with DD confirmed by MRI, Badel (2007a, 2008b) showed that $25 \%$ of them underwent orthodontic treatment (mainly by removable appliances), while in 5 asymptomatic subjects $(20 \%)$ DD was also determined. Nevertheless, since the asymptomatic group was a population of students of similar age, the share of those with previously performed orthodontic treatments was $40 \%$. Treatment by a fixed appliance was previously performed in an asymptomatic female subject with physiological disc position. Similarly, Katzberg et al. (1996) did not find any correspondence between orthodontic treatment and DD prevalence in patients $(77 \%)$ and also in asymptomatic subjects $(33 \%)$.

MRI provides better imaging of soft and hard TMJ structures and since it is not an invasive procedure, it is also used in children of the youngest age. Research has shown that DD is not a congenital disorder and according to Paesani et al. (1999), which has also been confirmed by clinical epidemiologic studies, develops only in older children and adults with the prevalence of as much as $45 \%$ (Haiter-Neto et al., 2002). However, studies do not show to what extent is asymptomatic DD related to a possible previous orthodontic treatment (Haiter-Neto et al., 2002).

Numerous studies of TMD patients confirmed the efficiency of MRI use with respect to clinical signs of the disorder (Moen et al., 2010). MRI was very useful in finding or controlling a therapeutic condylar position and its effects on the intraarticular function of TMJ, especially disc position. It has been used in long-term follow-ups of patients without evidence of serious progression of pathological changes in intraarticular structures (de Bont et. al., 1997). Even the subsequent occurrence of osteoarthritic changes in joints of DD patients during the follow-up period did not have clinical manifestations (Kurita et al., 2006). On the other hand, Tominaga et al. (2007) pointed to the changes in disc position with partial displacement occurring in the period of children's growth and development. This stresses the need for thorough analysis of TMJ on three representative layers in an oblique sagittal line in order to avoid doubts about the usefulness of MRI findings (Bumann \& Lotzmann, 2002), which still poses a problem of how to interpret the disc image with respect to its physiological position or anterior displacement (Petersson, 2010).

Jensen \& Ruf (2007) followed subclinical and clinical symptoms of TMD which were detected and managed by MFA in a group of students. In a period of 2.4 years on average, an increase of those with clinical signs of TMD occurred. Subclinical signs fluctuated a great deal yet one out of three students in the subgroup developed clinically manifested TMD. 


\section{Occlusion and TMD}

Occlusion was considered a possible etiopathogenic factor of TMD but their relationship is complex and still remains partially unexplained. Occlusal treatment is important not only to patients but also to dentists - nearly half of the interviewed Swedish dentists consider that the replacement of molars is necessary due to development of TMD and compromising of masticatory function (Lyka et al., 2001). The importance of occlusion in etiopathogenesis has been redefined by refuting the mechanistic conception which has been present from the beginning of scientific research of TMD. Loss of teeth and/or disorders of occlusion are certainly illnesses by nature but any type of irreversible occlusal treatment cannot be associated with causal treatment of TMD (Slavicek, 2009; Carlsson, 2010).

In an epidemiologic study, Gesch et al. (2004b) found a low incidence of certain variables of malocclusion (unilateral open bite, negative overjet and unilateral cross-bite in men, and edge-to-edge bite in women) with signs or symptoms of TMD. In both genders, anatomically correct occlusion was not significantly associated with TMD compared with malocclusions. By including static and dynamic factors of occlusion, a significant correlation with TMD incidence has been statistically determined but with a low correlation coefficient. Anterior open bite, deep overjet $6 \mathrm{~mm}$ or more, unilateral cross-bite and difference between centric relation and maximal intercuspidation amounting to more than $2 \mathrm{~mm}$ with more than six posterior teeth to be replaced can be considered increased risk factors for TMD (Pullinger et al., 1993). Conversely, Rammelsberg (1998) offered a review of etiopathogenic model of DD development wherein high abrasion and insufficient restorative procedure on posterior teeth are risk factors causing occlusal instability. In their research, $34 \%$ of patients with DD with reduction previously underwent orthodontic treatment. As opposed to that, only $16 \%$ of asymptomatic individuals and $14 \%$ of patients with DD without reduction were previously orthodontically treated. In order to further confirm the relationship between orthodontic treatment and development of TMD, a follow-up targeted study should be carried out prior to and after orthodontic treatment.

In a population of children, Pereira et al. (2009) did not find any correlation between malocclusion and TMD but they identified bruxism and posterior cross bite as risk factors for TMD. Tecco et al. (2010a) and Tecco \& Festa (2011) found a correlation between TMD with painful symptoms in children (5-15 years of age) and unilateral cross bite, but not with TMJ sounds. Myofascial pain was more prevalent in females. Huddleston Slater et al. (2007) found that age, history of orthodontic treatment, overbite and protrusion were significantly associated with DD with reduction. In their study, Badel et al. (2008b) found a significantly higher prevalence of hyperbalance and interference contacts in asymptomatic patients compared to TMD patients. No difference was found between Angle's classes in patients with DD and asymptomatic individuals. There was a statistically significant difference in teeth contact between the maximal intercuspidation and centric positions patients and asymptomatic subjects. Augthun et al. (1998) did not find any correlations between occlusal variables and forms of DD. However, it has been established that the rate of class II increases consecutively depending on the following subjects: asymptomatic subjects, patients with DD with reduction and patients with DD without reduction $(14 \% / 33 \% / 52 \%)$, while the share of subjects with class I decreases simultaneously $(43 \% / 30 \% / 18 \%)$.

Taking into account the great number of static and dynamic occlusal variables, it is difficult to comprehend the overall correlation with the development of TMDs due to the often non- 
standardised studies based on occlusal analysis (John, 1996). According to John et al. (1998), 'complex interaction' is the only but scientifically non-defined link between occlusion and TMDs. Occlusion ensures orthopedic stability of TMJ whereas the occlusal stability is ensured by mutually antagonistic contacts in a position of maximal intercuspidation. When the relationship between the two factors is compromised, it could lead to an overload of articular structures and consequently pose a risk of TMD development. The changes in occlusal relations are pronounced in etiopathogenesis, causing co-contraction of antagonist muscles the purpose of which is to protect the agonists and remove pain. The influence of possible adverse chronic effects can be avoided by the adaptation of muscular activity (Okeson, 2003).

The importance of occlusal interferences was perceived differently regarding the etiopathogenesis of TMDs. Le Bell et al. (2002) found that artificial interferences do not stimulate the development of dysfunctional symptoms in healthy subjects, instead they adapt successfully to them. In patients whose medical histories show TMD interferences stimulate the recurrence of stronger symptoms.

There is a dichotomy between scientific and clinical concepts of occlusion, which can be explained by the concept of integrated neurobiological system (Türp \& Schindler, 2003). Occlusion is a basic component of dental restorative procedures, which changes or supplements the compromised or lost occlusal relations in each segment of planning the procedure. Pathogenetic and therapeutic effects of myofascial pain can be explained only as a mutual relationship between occlusion and neuromusculature. The results of La Bella et al. (2002) are explained by the neurobiological hypothesis based on the differentiated activity of the part of the muscle in which increased tension and pain can occur. The changes in occlusal relations cause a mild unloading in painful muscles or within the structures of TMJ which means that different condyle positions during treatment can have the same effect. However, the mutual relationship between occlusal interferences and microtrauma has not been completely explained (Türp \& Schindler, 2003).

\subsection{Hypervigilance}

Reflex response to peripheral stimulus, that is, occlusal interference via periodontal receptors, can be modulated in the central nervous system in such a way that the stimulus causing normal opening in that case causes mouth closing. The hypothalamus and the limbic system mediate in tonus increase in affective conditions and under stress, whereas the reflex response to occlusal stimulus depends on the current state of agitation of those centres. In patients, even the slightest interference can produce the state of high stimulation and muscle hyperactivity, which can cause TMD at a lower level of adaptation. In other individuals with low level of activity of those centres an increase of muscle tonus due to occlusal interference does not occur. Parafunction is initiated only when the occlusal changes turn into a disturbance which leads to an awareness of pathological occlusal relations. A patient does not react to a harmful periodontal stimulus due to disturbed efficiency of behavioural mechanisms by diminishing the parafunction, instead it gains strength. Only in cases of hypervigilance, the occlusal changes will lead to TMD, due to increased awareness of one's own body and intensified activity of emotional motor system such as stress, pain or psychosocially caused parafunction. Hypervigilance is a changed form of observation wherein the harmful nociceptive stimuli are intensified (Hollins et al, 2009; Palla, 1998). 


\section{Concepts of TMDs treatment}

The concept of TMDs treatment procedures is indirectly connected with the already established symptoms and signs from the medical history and clinical examination. Since the exact pathophysiological mechanism of TMDs development has not been fully explained, the main goal of the treatment is the management, reduction and removal of temporomandibular pain. Treatment procedures are divided into reversible and irreversible procedures. Since the treatment is mostly empirical, that is, performed by evaluating the clinical significance if the established symptoms, the reversible procedures are mostly used. Treatment indications, type of treatment procedures and their practical application are based on the existence of a specific form of myogenic and/or arthrogenic disorder in the stomatognathic system accompanied by certain intensity of temporomandibular pain (Gremillion, 2002; Palla, 1998).

The course of development of neuroplastic processes in the central nervous system is prevented by the treatment of acute temporomandibular pain, and those processes result in development of chronic pain (pain present longer than 6 months). The treatment of temporomandibular pain is based on the following (Green, 2006; Palla, 1998, Palla, 2003):

- $\quad$ symptoms and clinical signs have complex features of musculoskeletal disorder;

- the morphofunctional features do not make the TMJ absolutely unique in the human body;

- occlusion is not a crucial etiopathogenic factor;

- patients are successfully treated by simple and non-invasive treatment procedures;

- the patient's psychological reaction should not be in proportion with the somatic pathology;

- the treatment approaches to non-chronic and chronic temporomandibular pain differ;

- the evaluation of the purposefulness and the optimal efficiency of the initial treatment is necessary.

\subsection{Aims and forms of the initial treatment}

The initial treatment comprises different and to a certain extent, specific procedures and means the main feature of which is to be as non-invasive as possible. The diagnosis should be discussed with the patient as well as its possible etiology and pathophysiology and the prognosis and its possible course of treatment. The patient should understand the diagnosis, especially if it is accompanied by chronic pain. Successfully informing the patient creates a placebo effect thus reducing the secondary induced psychological disorder which can compromise the success of the treatment. The patient is additionally motivated by the good prognosis of treatment. Diet consisting of soft food is recommended as well as instructions on how to change oral activity in the sense of self-observation and self-correction of oral habits and parafunctions (Green, 2006).

Physical and manual therapy plays an important role in treatment of all rheumatic disorders and at the same time it actively involves the patient in the course of the treatment. The aim is to remove musculoskeletal restrictions such as pain removal, detoning and stretching of hypertonic muscles. Therapy is conducted by ultrasound, TENS, laser, kinesiotherapy by Schulte, localised massage, etc. (Badel et al., 2010b). Nonsteroidal anti-rheumatics are indicated in acute pain of different etiologies. Due to systemic side-effects in the gastrointestinal tract and due to blood circulation disorders in kidneys, it $\mathrm{s}$ recommended to 
prescribe selective inhibitors of the prostaglandin synthesis which should be taken during a longer period of time (Badel et al., 2007b).

The irreversible treatment mostly implies surgical procedures. Arthrocentesis (removal of inflammatory exudate), surgical reposition of articular disc (arthrotomy), discectomy, placement of articular disc implants and condylectomy can be performed on the TMJ. Arthroscopy is a diagnostic-treatment method used for imaging of intraarticular pathologic changes with the possibility of their simultaneous removal (Machon et al., 2010; Palla, 1998).

\subsection{Occlusal splints}

The occlusal splint is the most common and efficient treatment procedure of arthrogenic and/or myogenic forms of TMDs and bruxism. The occlusal stability is established by specific morphology of the splint which is placed on the teeth alignment of one jaw thus serving as an orthopedic means of TMJ stabilisation (de Leeuw, 2008; Okeson, 2003). The occlusal splint is used as a temporary means of obtaining therapeutic occlusion and as a preparatory stage for definite prosthetic treatment (Badel, 2003).

Depending on the indications of use and treatment effects of the occlusal splint, hyperactivity is reduced, that is, the masticatory muscles are relaxed, the condyle is therapeutically positioned, that is, placed into the centric relation position and the behavioural effects increase awareness about the position, function and parafunction of the mandible thus achieving placebo effect (Dylina, 2001).

\subsubsection{Classification of occlusal splints}

In occlusal splint treatment the following changes occurred in: biomechanic concepts of their effects, features of their placement and retention on the teeth, morphology of the occlusal plane of the splint and their effect on the position and movements of the mandible.

Relaxation splints are used in the treatment of bruxism as well as in management of arthrogenic and myogenic temporomandibular pain. The Michigan splint (occlusal bite plane stabilisation splint with cuspid rise and freedom in centric) by Ramfjord and Ash is a splint covering all the teeth in the jaw, enabling antagonistic contacts on the flat planes according to occlusal concepts of freedom in centric position. Guiding by canines along the modelled planes of the splint is achieved in each extracentric movement (Ash \& Schmieseder, 1999).

Distraction splint (pivot splint) vertically unloads intraarticular structures by condyle distraction and is indicated in arthroses, perforation of articular disc and anterior DD without reductiong. The splint acts as a hypomochlion in individual bilateral contacts in the molar region, by which distraction (decompression) of TMJs is obtained (Okeson, 2003).

Repositioning (protrusion/distraction) splint causes the excentric (anterior) positioning of the mandible and is used for treatment of anterior displacement of the articular disc with repositioning. The aim of the splint treatment is repositioning of the articular disc into the physiological position with respect to the condyle, which is achieved by its occlusal plane. The splint achieves a protrusive (anterior) position of the condyle with a slight distraction effect on the TMJs (Okeson, 2003). 
With respect to the variety of design characteristics and the biomechanical effect of occlusal splints, previous concepts of initial treatments have been revised. The effect of anterior displacement/position of the articular disc and subsequent irreversible changes in physiological occlusal relations is questionable. Stabilisation of the mandible in anterior position leads to intraarticular partitioning which can lead to permanent anterior habitual occlusion resulting in malocclusion (back open bite due to extrusion of posterior teeth and orthodontic displacement of anterior teeth) (Brenkert, 2010). In order to avoid irreversible, unwanted changes in the structures of the masticatory system, the Michigan splint is the device of choice due to the proved beneficial effect in alleviation and removal of symptoms TMDs (Badel, 2009b). The occlusal splint, according to the individual case, is combined to a certain extent with other forms of initial treatment of TMDs. In treatment of DD, it is important to consider that repositioning of the articular disc is not satisfactory in as much as $50 \%$ of cases and recurrences are possible in $1 / 3$ of the cases (Le Bell \& Kirveskari, 1990).

\subsection{Implications of orthodontic treatment on TMD}

Orthodontic treatment can be viewed from two different points of view: whether orthodontic treatment has a negative impact on development of signs and symptoms of TMDs and what the role of orthodontic treatment is regarding the modality of TMDs treatment. MRI helped with detection, that is, follow-up of the influence of orthodontic treatment on the intraarticular structures of TMJ. In a group of 15 orthodontic patients (aged between 12 and 17) Pancherz et al. (1999) found clinical signs of TMD in two patients (partial DD in one patient and osteoarthritic changes in the other). All orthodontic patients wore a Herbst appliance during 7 months due to Class II malocclusion. In the follow-up period, DD improved (metric evaluation) and in the other patient, the loss of osteoarthritic changes was considered the result of compensatory joint remodelling. Aidar et al. (2006) performed a metric evaluation of the effects of Herbst treatment in adolescents with Class II Division 1 malocclusion. There was no significant influence of orthodontic treatment on DD development.

Tullberg et al. (2001) conducted a research with a follow-up on the correlation between early (children with primary dentition) and late (children with mixed or permanent dentition treatment of unilateral posterior cross-bite. There was no evidence that early treatment, even the later treatment repeated in 11 out of 44 subjects, was related to significant development of signs and symptoms of TMD. Therefore, even in a case of malocclusion as a risk factor, orthodontic treatment could not be related to the development of TMD. Even the first (early) orthodontic treatment could be repeated in older age (as a late treatment) and the subjects aged 19 would not have more significantly manifested TMD. During a 4-month follow-up, Bourzgui et al. (2010) did not find any correlation between development of TMD symptoms and Angle classes. Although the unilateral posterior cross bite is mentioned as a significant variable in DD of TMJ, in a group of children (average age of 9.3 years) their correlation could not be established by MRI analysis (Pellizoni, 2006).

During a long follow-up, Egermark et al. (2003) investigated the relationship between occlusal variables and development of clinical signs and symptoms of TMDs. From a longterm perspective, subjects were very pleased with the orthodontic treatment, and the treatment received in childhood did not increase the risk for TMDs later in life. In some subjects, lateral forced bite between retruded contact position and intercuspal position, as well as unilateral cross bite might be of importance in this respect. Henrikson \& Nilner 
(2003) followed the clinical signs and symptoms of TMDs during the fixed orthodontic treatment, especially in girls with Class II malocclusion. They were compared with girls who did not receive treatment and controls with normal occlusion. It was observed that signs and symptoms of TMDs equally develop in all three groups and, over time, they fluctuate considerably and unpredictably. A part of patients with Class II and the myogenic form of TMDs even experienced improvement of their condition due to orthodontic treatment. In any case, fixed orthodontic treatment did not particularly aggravate TMDs compared to the pre-treatment period.

Tecco et al. (2010a) compared the efficiency of TMDs treatment by a fixed orthodontic appliance and the anterior repositioning splint. DD was diagnosed by MRI and the effect of both treatments was beneficial to treatment of myogenic and arthrogenic pain, whereas the repositioning splint proved to be more efficient for removal of pathological noise in the joint. Siegmund \& Harzer (2002) showed a detailed orthodontic treatment of a patient with DD. Clinical diagnostics was based on MFA and it was supplemented by axiography. The need for pre-treatment diagnostics and treatment planning was stressed which leads to a successful outcome of fixed orthodontic treatment as well as to the avoidance of complications related to possible exacerbation of TMD symptoms.

Jensen \& Ruf (2007) showed that during a long-term orthodontic treatment, significant development of TMD is not to be expected. Likewise, the transformation of subclinical signs into clinical signs of TMD can be expected, which should not be associated with the course of possible orthodontic treatment. Although the results of the above mentioned studies reveal that orthodontic treatment does not have a special effect on the condition of TMDs, it should be taken into account that the studies described the treatment which was indicated for entirely orthodontic reasons. However, each treatment, particularly irreversible ones, runs the risk of adverse effects. Condylar resorption is one of the iatrogenic examples of TMDs development possibly related to orthodontic treatment. Orthodontic forces can often cause undesired reactions of partitioning within the alveolar bone. As in the described case, TMD symptoms were not observed on time thus causing the lack of consistent radiological follow-up (Shen et al., 2005).

Idiopathic condyle resorption is the term for the progressive form of OA of TMJ, which is associated with trauma and orthopedic procedure. Although it is an unwanted complication or an independent pathologic process manifested during orthodontic treatment, it certainly gives an impression of failure and of an even worse condition of the stomatognathic system. In the above mentioned study of patients with DD (Badel, 2007a), in the course of the follow-up of intraarticular condition during the treatment by Michigan splint, a rapid osteoarthritic process in a female bruxist patient with unilateral anterior DD without reduction and also malocclusion of Class II division 1 was found by MRI. Condyle resorption resulting in drastically pronounced open bite was not accompanied by exacerbation of TMD symptoms.

\section{Clinical case}

A 26-year-old female patient, previously under orthodontic treatment, was referred to a prosthodontic specialist, complaining of pain in her right TMJ and clicking in the left one with limited mouth opening. The pain was intensified upon chewing. 
Patient's history. Without any particular reason, the patient experienced clicking in her left TMJ and she contacted her dentist, which happened 7 months prior to her visiting the prosthodontist. Her dentist referred her to an orthodontist. She was treated by a bimaxillary removable appliance (bionator) in order to correct a large horizontal overjet (Angle class II/1).

In the course of the orthodontic treatment, the patient still complained about the clicking and after 4 months pain in the right TMJ appeared. She had difficulties opening her mouth, pain appeared upon each movement of the mandible; she had difficulties adjusting to the new occlusal relations established by the orthodontic appliance and had a swelling in the region of the right TMJ. With respect to the above mentioned symptoms, she felt more comfortable in habitual occlusion than in the anterior therapeutic position achieved by the bionator. However, the patient did not realise at first that the pain in the TMJ was not being treated. The orthodontist did not realise that her intention was not to treat the orthodontic anomaly. Since the treatment by bionator obviously did not affect the TMJ symptomatology in that period, and her condition even worsened, the patient realised that her problems were not resolved by the treatment - instead of the TMJ symptoms she was treated for the orthodontic anomaly. According to the patient, the orthodontist realised this and attempted to stop the treatment by bionator without any particular explanation or further counselling with colleagues.

Occlusal analysis. At the first intraoral examination of the patient, two habitual intercuspal positions were detected. Until the lips were spread apart for a detailed dental examination, there was an impression of a physiological relationship between the anterior teeth. However, it was an acquired and forced anterior bite caused by regular wear of the bionator. In this position, the posterior teeth were in non-occlusion (Figure 3).
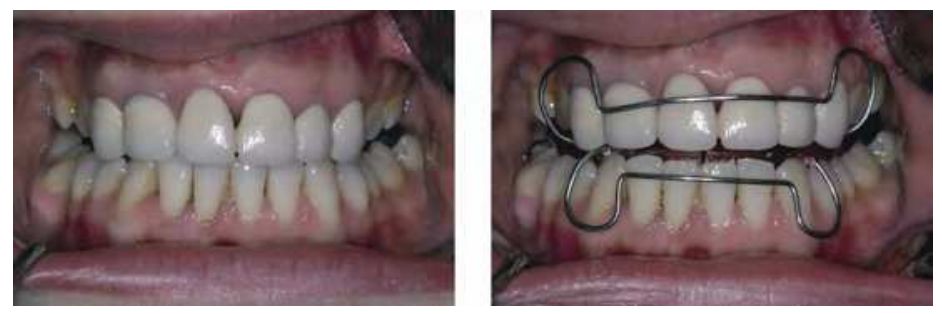

Fig. 3. Occlusion in anterior forced bite without (left) and with inserted bionator (right) in the mouth.

The real anterior-posterior relations between the dental arches were shown in the habitual intercuspal position: Angle Class II/1, an $11 \mathrm{~mm}$ horizontal overjet and a $4 \mathrm{~mm}$ overbite of upper teeth over the lower ones. In the transversal plane there was a $1 \mathrm{~mm}$ displacement of the medial line between lower central incisors to the right compared with the upper central incisors due to the loss of previously extracted first molars, especially of the extracted tooth 46 (Figure 4). In both teeth alignments, there was a crowding of posterior regions. The upper anterior teeth were provided with ceramic crowns. In both lateral movements there was a canine guidance, without balanced contacts or interferences. The teeth did not show any clinical signs of dental abrasion. 

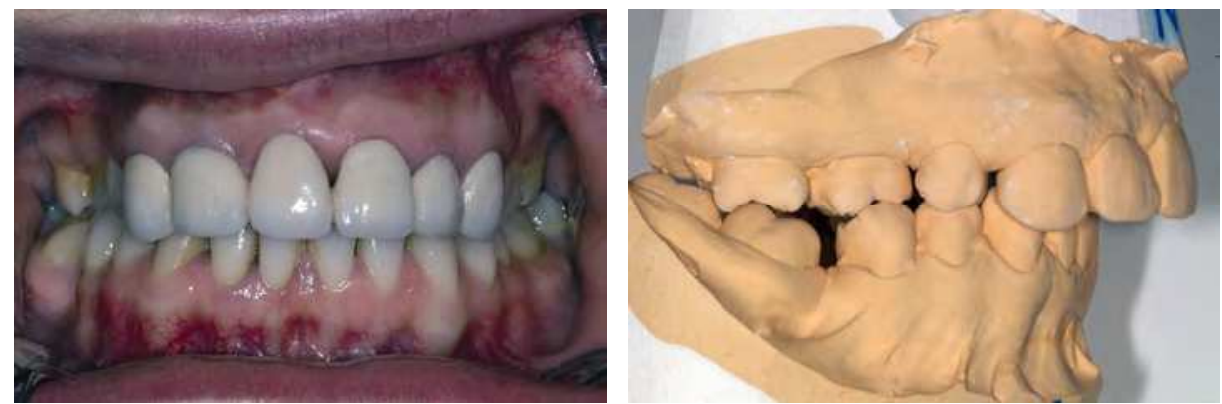

Fig. 4. Habitual occlusion in maximum intercuspidation (left), and lateral view of the model transferred to the articulator. Note: a pronounced horizontal overjet (right).

Clinical diagnostics. Painful right TMJ with limited mouth opening was diagnosed by clinical examination and MFA according to Bumann and Groot Landeweer (Bumann and Lotzmann, 2002). Active mouth opening amounted to $36 \mathrm{~mm}$, whereas passive mouth opening, that is mouth opening by exerting a mild downward passive force on the lower incisors amounted to $41 \mathrm{~mm}$. Protrusive movement amounted to $6 \mathrm{~mm}$, laterotrusion to the right amounted to $8 \mathrm{~mm}$ and laterotrusion to the left amounted to $4 \mathrm{~mm}$. The pain intensity on the visual-analogue scale (VAS) (VAS=0-10; 0-10; 0 , no pain; 10 , the worst pain) was rated 7.4. On mouth opening there was a deviation to the right. On the right and also left laterotrusal movement, the pain appeared only in the right TMJ. Based on clinical findings and according to MFA (painful right TMJ under active and passive compressions) an anterior DD without reduction in the right TMJ was confirmed. Since the clinical signs of the disorder of the left TMJ were not present (the patient stated that she previously experienced reciprocal clicking), a clinical diagnosis of the left TMJ could not be made.

Radiological diagnostics. Panoramic x-ray shows a non-symmetrical relationship between the left and the right condyle: the right condylar head is pointed with a deplaned anterior surface. The bilateral anterior DD was confirmed by MRI. Imaging of both TMJs was performed on a 1T magnetic field device in three different positions: closed mouth position (habitual maximal intercuspidation, anterior position of the mandible caused by orthodontic treatment and open mouth position). The imaging sequences (matrix $256 \times 192 ; 160 \times 160$ field of view) included the T1 weighted image (TR 450/TE 12), and gradient echo T2 weighted image (TR 760/TE 32), and T2 weighted image (TR 3000/TE 72).

Anterior DD without reduction was confirmed, with collections of inflammatory exudates which are most visible on T2 weighted images (Figure 5). In closed mouth position, the condylar head is anteriorly dislocated (Figure 5a), which is more visible in a forced anterior position (Figure 5b). Further dislocation is minimal (open mouth position) while the disc is constantly anteriorly dislocated and is deformed (Figure 5c). The condyle reaches the peak (zenith) of the articular eminence. Mild osteoarthritic changes in cortical bone of the condylar head in slightly pointed forms without subchondral changes are visible.

The anterior DD with reduction was determined in the left TMJ (Figure 6), which explains the previous symptom of clicking, which vanished in the course of orthodontic treatment. In closed mouth position, the condylar head was centrically placed within the glenoid fossa 
but in a slightly distraction position resulting in an enlarged intra articular fissure (Figure $6 a)$. The disc was placed anteriorly and remained in this position even when the patient's mandible was in a forced anterior position (Figure 6b). In open mouth position, the disc achieved physiological position with respect to the condyle but it did not reach the peak of the articular eminence (Figure 6c). However, the mobility of the left condyle is more pronounced than in the right joint. The condylar head was slightly pointed with a hint of osteoarthritic changes appearing as a thickened tip of the cortical bone. Subchondral structures had an adequate signal and there was no articular effusion.

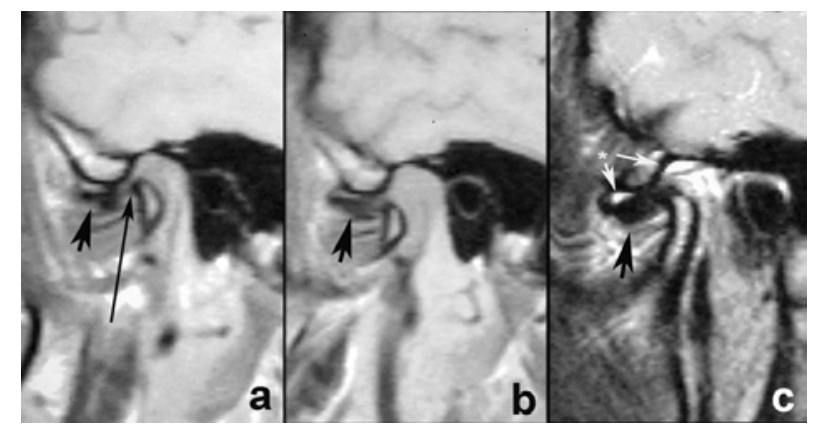

Fig. 5. Magnetic resonance images of the right temporomandibular joint in the position of maximum habitual intercuspidation (a), forced anterior position (b) and open mouth position (c). Note: non-reduced anterior displaced disc (short arrow), joint effusion (marked with *), and degenerative changes of cortical condylar head (long arrow).

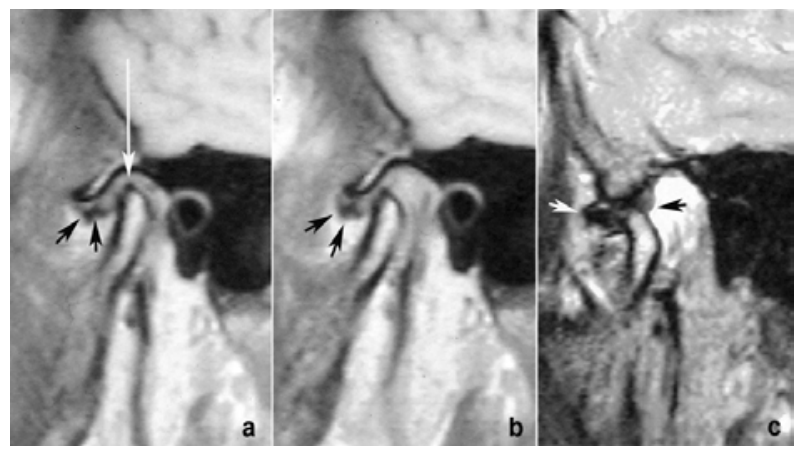

Fig. 6. Magnetic resonance images of the left temporomandibular joint in the position of maximum intercuspidation (a), forced anterior position (b) and open mouth position (c). Note: anterior displaced disc with reduction (short arrows) and degenerative changes of anterior part of cortical condylar head (long arrow).

Treatment. The stabilization splint (according to some authors the Michigan splint) (Badel, 2007a) is indicated for the initial treatment of pain caused by anterior DD (Figure 7). It temporarily provides stable joint position, and in addition, reduces abnormal muscle activity. Both jaw alginate impressions were taken and the splint was fabricated in a new therapeutic position, that is, in a position of centric relation. This was also the best position 
for stabilization splint fabrication since it ensures a stable position of condyle in the articular fossa. It also enables the removal of the retrodiscal tissue load exerted by the condyle since the articular disc is permanently protruded, that is displaced anteriorly (Badel et al., 2003). The patient was instructed to wear the appliance while sleeping and was asked to come for a check-up in a week.
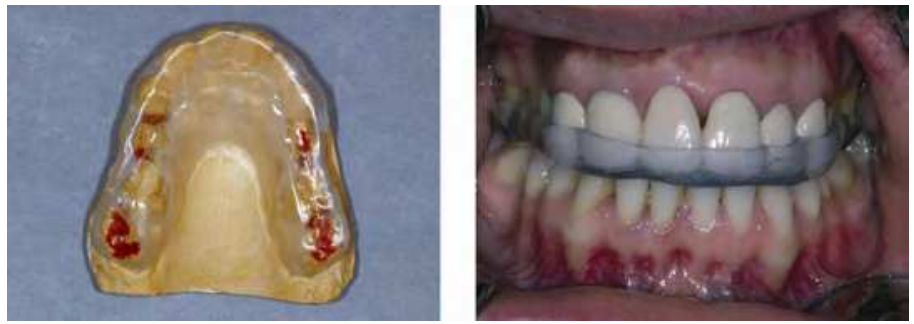

Fig. 7. Michigan splint on a model (left) and the inserted splint in the patient's mouth (right).

In collaboration with a rheumatologist-physiatrist, the patient was referred to physical therapy, which consisted of a routine protocol: TENS (transcutaneous electroneural stimulation), topical non-steroidal analgesic ketoprofen (Fastum gel) three times a day and a kinesiotherapy programme by Schulte (Badel et al., 2010b). She continued performing the exercises by Schulte three times a day at home.

Besides stopping the orthodontic treatment, the patient initially wore the Michigan splint for about 5 months. After 6 months, a more significant ability of mouth opening $(45 \mathrm{~mm})$ was measured but pain in both joints was still present, particularly upon yawning (VAS=8). While the left joint was painful on wider mouth opening, pain in the right joint was more expressed and accompanied by slight crepitations. The patient was aware of the chronic nature of her pain because, as she stated, she 'got used to' the pain. She stressed the efficiency of oral exercises and topical application of the ketoprofen gel (Fastum gel).

Long year follow-up. At a recall 5 years later, the patient did not have pain in the TMJs and only felt discomfort in the right TMJ during wide mouth opening with clinically evidenced minor crepitations. However, she felt discomfort in the right joint on yawning ad sleeping on the right side of her face. When eating an apple and yawning, she sometimes felt pain in the right joint $(\mathrm{VAS}=4)$. Also, she mentioned rare occurrences of clicking in the right joint which was also painful. Maximum mouth opening still amounted to $45 \mathrm{~mm}$, which is significant regarding the pre-treatment measurements and equal to the measurements after the initial treatment. Now, she does not have any esthetic or functional needs for orthodontic treatment.

A control MRI taken on the same device showed visible degenerative changes in both TMJs. Significant changes in the sense of OA development occurred in the right joint: the condyle was deplaned and an osteophytic formation on the anterior edge contributed to the unshapely appearance. The disc was deformed with anterior displacement (Figure 8a). Even in the anterior position, the disc still remained in front of the condyle (Figure $8 \mathrm{~b}$ ). In open mouth position, the condyle reached the eminence while the disc remained nonreduced (Figure $8 \mathrm{c}$ ). 


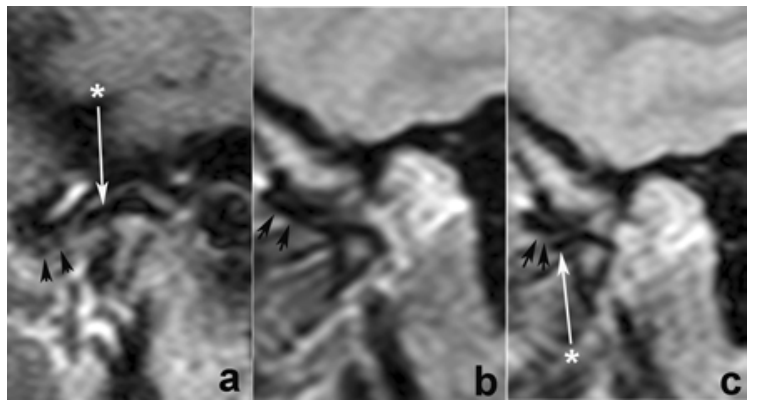

Fig. 8. Follow-up examination of the right temporomandibular joint by magnetic resonance imaging in the position of habitual maximum intercuspidation (a), forced anterior position (b) and open mouth position (c). Note: non-reduced and deformed anterior displaced disc (short arrow) and the osteophyte formation on the anterior edge of the condyle (long arrow).

In closed mouth position (habitual occlusion), a compensatory fibrosation of retrodisc tissue along with the deplaned condylar head of an appropriate size was visible in the left joint (Figure 9a). In the forced anterior position, the greatest part of the disc was placed anteriorly from the condyle (Figure 9b), whereas there was an almost complete reduction of displacement in open mouth position, that is, the disc was almost symmetrically repositioned on the condyle (Figure 9c). The condyle-disc complex almost reached the peak of the eminence when the patient wore the bionator, and also in the position of maximum mouth opening.
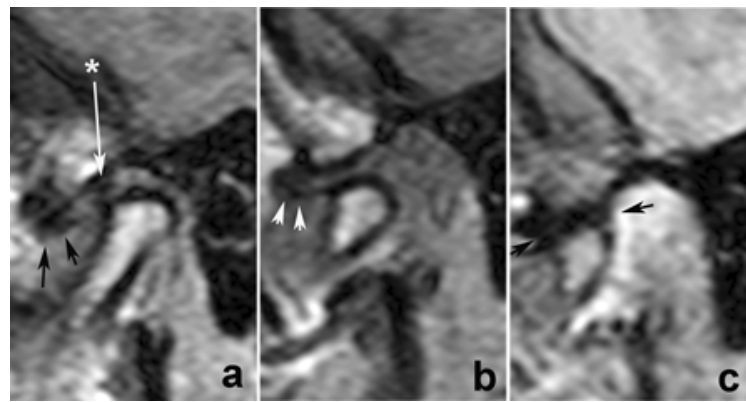

Fig. 9. Follow-up examination of the left temporomandibular joint by magnetic resonance imaging in the position of habitual maximum intercuspidation (a), forced anterior position (b) and open mouth position (c). Note: disc displacement with reduction (arrows), and fibrosation of the retrodisc tissue (marked with *).

\section{Discussion and general remarks}

Orthodontic treatment should be planned carefully if there are underlying symptoms of TMDs. Clinical importance of certain dysfunctional symptoms has altered the concept of normal functioning of the stomatognathic system. A perfected interpretation of certain diagnostic symptoms enables the correct establishing of clinical diagnostic parameters and other diagnostic modalities of TMDs. The approach to patient in the sense of personalised 
dental medicine gains importance when dealing with patients suffering from certain diagnoses of TMDs. Furthermore, the issue of occlusion in dental medicine has reached a dogmatic level, which in case of TMD patients should not apply, particularly the use of irreversible treatment methods as well as planning of possible preventive procedures (Carlsson, 2010).

As with many other musculoskeletal disorders in the human body, according to modern biomedical beliefs, they are of non-specific etiopathology, that is, they are idiopathic on the level of the individual patient (Green, 2006). Correlating TMDs with numerous etiopathogenic factors does not result in efficient determination of their cause-effect relation. Therefore, current opinion is that TMDs are idiopathic in origin and the correlation with certain etiologic factors cannot be entirely confirmed; on the other hand, the question of chronic musculoskeletal (or non-malignant) pain becomes dominant within the field of pain medicine. Consequently, pain and TMDs cannot be observed only on the level of occlusion, individual patients' wishes regarding esthetic dentistry and relying on scientifically unverified but traditional treatment indications.

Clinical examination, particularly manual examination techniques of patients with TMDs are an indispensable part of diagnostics by which the indication for imaging techniques is determined. MRI has become the gold standard in diagnostics and differential diagnostics of TMDs because it enables imaging of hard and soft tissues of TMJ (primarily the disc) and joint effusion. Although MRI is the gold standard in TMJ diagnostics, there is still no gold standard in diagnostics of temporomandibular pain. Indeed, MRI is not an appropriate screening method but a strictly applied diagnostic and differential-diagnostic method (Ahmad et al., 2009).

TMDs treatment planning can be carried out as the initial treatment and upon reaching a satisfactory degree of recovery, the definitive treatment can be planned as well. This may be applied to all TMDs patients, regardless of their having intact teeth with respect to physiological occlusal relations as well as to patients in need of orthodontic or prosthodontic treatment or even an oral surgical procedure. One should bear in mind the fact that definite treatment should have its indications and should be in accordance with the patient's wishes as well as with the actual state of occlusion and the level of TMDs treatment. In managing of TMDs patients there are always doubts about the indications for definite treatment, if there was a possibility of treating the painful TMD only by reversible treatment modalities, that is, by initial treatment. By recognizing the signs and symptoms of TMDs and by choosing initial methods of treatment as the methods of choice, the excessive use of diagnostics (for example, MRI) as well partial or complete overtreatment modalities are avoided (De Boever, et al., 2008; Türp, 2002).

The possibility of incorrect treatment in cases of TMDs patients can happen as it was shown in the clinical case of the female patient described in this paper, which was contrary to her wishes and individual needs of malocclusion treatment. Excessive, unnecessary and incorrect treatment methods of TMDs patients can have legal repercussions (Manfredini et al., 2011).

The patient has a input in the planning of own treatment and the dentist should consider the patient's wishes, and the current trend is to collaborate with other dental and medical specialists which is a multidisciplinary approach (De Boever et al., 2008). 
Since clinical TMDs symptoms range from painless clicking up to severe pain causing problems in basic functioning upon eating and speech, the question arises when TMDs symptoms should be treated. In cases of adolescent patients with an occlusal anomaly there are considerations of whether orthodontic treatment can prevent their exacerbation, particularly pain. Since prevention implies the possibility of affecting causal factors of the disease, there is a lack of scientific facts to support that (Luther, 1998).

The absence of temporomandibular pain and mild functional difficulties caused by remaining TMD symptoms represent the group of passive need for TMD treatment. The idiopathic concept of development of TMDs cannot accept the concept by Kutilla et al. (1996) of active and passive TMD prevention. Preventive measures cannot be planned in patients with unknown etiology. Since the topic of this paper is the relationship between orthodontics and TMDs (although numerous studies are not methodologically coordinated and neither is the sample of patients who are primarily orthodontic or primarily with TMDs), the review papers on this subject constantly reach the conclusion that orthodontics neither treats TMDs nor causes them in particular (Macfarlane et al., 2009). As it happens in every definitive treatment in the stomatognathic system, painful forms of TMDs aggravate orthodontic treatment which was previously planned due to malocclusion rather than TMDs. In the course of orthodontic treatment previously latent symptoms of TMDs may appear (that is why MFA is significant as a clinical screening test) or manifested TMDs symptoms may develop although the patient did not experience such symptoms at any level prior to this. Such a condition particularly aggravates further orthodontic treatment so that it is recommended to temporarily discontinue the orthodontic treatment according to the need and the level of the presence of symptoms (Michelotti \& Iodice, 2010). The part of the functional treatment termed initial symptomatic treatment, which should provide a satisfactory degree of painful function of stomatognathic system, should be carried out in order to continue the orthodontic treatment (Badel, 2007a).

In a review of methods of clinical TMD evaluation in population of children and adolescents, Toscano \& Defabianis (2009) pointed to a great variability of results which causes problems in their direct possibility of comparison. However, it can be concluded that joint sounds and TMJ symptoms are the most common in that subgroup of population. Bionators initially look like a sort of combined upper and lower Hawley retainer, but do not fasten to the teeth and are not used for post-brace removal treatment. Bionators are held in the mouth within the space that the teeth surround when biting. In the described clinical case, a distinction should be made between short-term wear of bionator and the exacerbation of painful clinical signs and symptoms of TMD as well as manifestation of osteoarthritis with prior DD within a 5-year-follow-up, which was confirmed by MRI. Such long-term effects of MRI imaging of TMJs cannot be ascribed to orthodontic treatment because degenerative changes accompanied by various conditions of DD, according to Kurita et al. (2006) develop even without any clinical symptoms. After all, DD of TMJ can be expected even in asymptomatic subjects (Badel et al., 2008c).

According to the American Academy of Pediatric Dentistry (2010) there are reversible and irreversible methods of TMD treatment. Irreversible methods of treatment include occlusal adjustment, mandibular repositioning (by a repositioning appliance) and also orthodontic treatment, without specific instructions on which group of treatment modalities is recommendable. Regarding the use of reversible treatment methods, there are some positive 
results obtained by, for example, Tecco et al. (2010) who found a positive effect of a fixed orthodontic appliance and the anterior repositioning splint on TMDs. Arthrocentesis proved to be efficient in combination with the occlusal splint (Machon et al., 2011). The use of the repositioning splint should be controlled and short-term because it can result in development of posterior open bite as a result of partitioning of intraarticular structures of TMJ on forced anterior bite (Türp, 2002; Brenkert, 2010). In such a case the initial treatment can be a failure because repositioning of this kind does not imply moving the anteriorly displaced disc (displacement reduction) but moving the condyle into a position which reduces the displacement thus causing clicking. Asymptomatic causes in non-patients show that DD does not necessarily mean the appearance of symptoms suggesting that such causative treatment is not in accordance with the principle of symptomatic treatment of TMDs (Badel et al, 2008c; Türp, 2002). When choosing the right initial occlusal treatment, permissive and non-invasive occlusal splints, such as the Michigan splint, are given the advantage (Dylina, 2001).

Optimal cost-effectiveness and health care efficiency are achieved by using palliative treatment procedures which cannot result in potentially incorrect, excessive, insufficient or untimely treatment of TMDs (Figure 10).

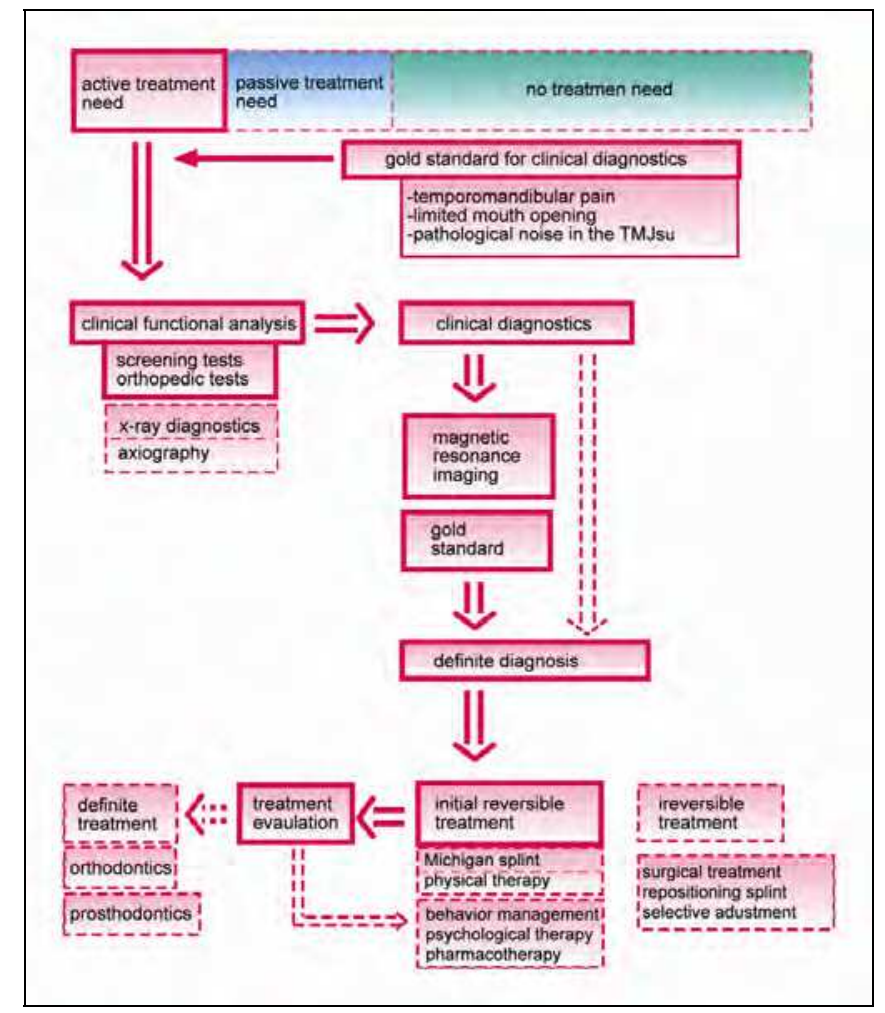

Fig. 10. The relationship between diagnostic and treatment procedures in patients with temporomandibular disorders. 


\section{Acknowledgment}

This paper is a part of the scientific project No. 065-0650445-0441 supported by the Ministry of Science, Education and Sports, Republic of Croatia.

\section{References}

Aidar, L.A.; Abrahão, M.; Yamashita, H.K. \& Dominguez, G.C. (2006). Herbst appliance therapy and temporomandibular joint disc position: a prospective longitudinal magnetic resonance imaging study. American Journal of Orthodontics and Dentofacial Orthopedics, Vol.129, No.4, pp. 486-496, ISSN 0889-5406

Ahmad, M.; Hollender, L.; Anderson, Q.; Kartha K.; Ohrbach, R.; Truelove, E.L.; John, M.T. \& Schiffman, E. (2009) Research diagnostic criteria for temporomandibular disorders (RDC/TMD): development of image analysis criteria and examiner reliability for image analysis. Oral Surgery, Oral Medicine, Oral Pathology, Oral Radiology, and Endodontics, Vol.107, No.6, pp. 844-860, ISSN 1079-2104

American Academy on Pediatric Dentistry Clinical Affairs Committee. (2010) Guideline on acquired temporomandibular disorders in infants, children and adolescents. Pediatric Dentistry, Vol.32, No.6, pp. 232-237, ISSN 0164-1263

Ash, M.M. \& Schmieseder, J. (1999) Schienentherapie. Urban \& Fischer, ISBN 3-437-05030-3, München, Germany

Augthun, M.; Müller-Leisse, C.; Bauer, W.; Roth, A. \& Speikermann, H. (1998) Anterior disk displacement of the temporomandibular joint. Significance of clinical signs and symptoms in the diagnosis. Journal of Orofacial Orthopedics, Vol.59, No.1, pp 39-46, ISSN 1434-5293

Badel, T.; Pandurić, J.; Kraljević, S. \& Dulčić, N. (2003) Initial Treatment of Prosthetic Patients with a Michigan Splint. Acta Stomatologica Croatica, Vol.36, No.2, pp. 207210, ISSN 0001-7019

Badel, T.; Kraljević, S.; Pandurić, J. \& Marotti, M. (2004) Preprosthetic therapy utilizing a temporary occlusal acrylic splint: A case report. Quintessence International, Vol.35, No.5, pp. 401-405, ISSN 0033-6572

Badel, T. (2007a) Temporomandibularni poremećaji i stomatološka protetika. Medicinska naklada, ISBN 978-953-176-264-9, Zagreb, Croatia

Badel, T.; Rošin Grget, K.; Krapac, L. \& Marotti, M. (2007b) Principi farmakoterapije temporomandibularnih poremećaja. Medicus, Vol.16, No.2, pp. 241-250, ISSN 1330013X

Badel, T.; Lajnert, V.; Marotti, M.; Krolo, I. \& Kovačević Pavičić, D. (2008a) Poremećaj čeljusnog zgloba u 12-godišnje pacijentice. Medicina. Vol.44, No.1, pp. 91-97, ISSN 0025-7729

Badel, T.; Marotti, M.; Krolo, I.; Kern, J. \& Keros, J. (2008b) Occlusion in patients with temporomandibular joint anterior disk displacement. Acta Clinica Croatica, Vol.47, No.3, pp. 129-136, ISSN 0353-9466

Badel, T.; Pandurić, J.; Marotti, M.; Kern, J. \& Krolo, I (2008c) Metrička analiza temporomandibularnog zgloba magnetskom rezonancijom $\mathrm{u}$ asimptomatskih ispitanika. Acta Medica Croatica, Vol.62; No.5, pp. 455-460. ISSN 1330-0164 
Badel, T.; Marotti, M.; Keros, J.; Kern, J. \& Krolo, I. (2009) Magnetic Resonance Imaging Study on Temporomandibular Joint Morphology. Collegium Antropologicum, Vol.33, No.2, pp. 455-460, ISSN 0350-6134

Badel, T.; Marotti, M.; Kern, J. \& Laškarin, M. (2009) A quantitative analysis of splint therapy of displaced temporomandibular joint disc. Annals of Anatomy, Vol.191, No.3, pp. 280-287; ISSN 0940-9602

Badel, T.; Carek, A.; Podoreski, D.; Pavičin, I.S. \& Lovko, S.K. (2010a) Temporomandibular joint disorder in a patient with multiple sclerosis--review of literature with a clinical report. Collegium Antropologicum, Vol.34, No.3, pp. 1155-1159, ISSN 03506134

Badel, T.; Krapac, L. \& Marotti , M. (2010b) Dijagnostika i fizikalna terapija osteoartritisa temporomandibularnog zgloba. Medix, Vol.16, No.89-90. pp. 214-244, ISSN 13313002

Benoliel, R. \& Sharav, Y. (2010) Chronic orofacial pain. Current Pain and Headache Reports, Vol.14, No.1, pp. 33-40, ISSN 1531-3433

Bonjardim, L.R.; Gaviao, M.B.; Carmagnani, F.G.; Pereira, L.J. \& Castelo, P.M. (2003) Signs and symptoms of temporomandibular joint dysfunction in children with primary dentition. The Journal of Clinical Pediatric Dentistry, Vol.28, No.1, pp. 53-58, ISSN 1053-4628

Bourzgui, F., Sebbar, M.; Nadour. A. \& Hamza, M. (2010) Prevalence of temporomandibular dysfunction in orthodontic treatment. International Orthodontics, Vol.8, No.4, pp. 386-398, ISSN 1761-7227

Brenkert, D.R. (2010) Orthodontic treatment for the TMJ patient following splint therapy to stabilize a displaced disk(s): a systemized approach. Part II. Cranio: the Journal of Craniomandibular Practice, Vol.28, No.4, pp. 260-265, ISSN 0886-9634

Bumann, A. \& Lotzman, U. (2002) Funktionsdiagnostik und Therapieprinzipien. Thieme, ISBN 3-13-787501-3, Stuttgart, Germany

Carlsson, G.E. (2010) Some dogmas related to prosthodontics, temporomandibular disorders and occlusion. Acta Odontologica Scandinavica, Vol.68, No.6, pp. 313-322, ISSN 00016357

Casanova-Rosado, J.F.; Medina-Solís, C.E.; Vallejos-Sánchez, A.A.; Casanova-Rosado, A.J.; Hernández-Prado, B. \& Avila-Burgos, L. (2006) Prevalence and associated factors for temporomandibular disorders in a group of Mexican adolescents and youth adults. Clinical Oral Investigations, Vol.10, No.1, pp. 42-49, ISSN 1432-6981

De Boever, J.A.; Nilner, M.; Orthlieb, J.D. \& Steenks, M.H. (2008) Recommendations by the EACD for examination, diagnosis, and management of patients with temporomandibular disorders and orofacial pain by the general dental practitioner. Journal of Orofacial Pain, Vol.22, No.3, pp. 268-278, ISSN 1064-6655

de Bont, L.G.; Dijkgraaf, L.C. \& Stegenga, B. (1997) Epidemiology and natural progression of articular temporomandibular disorders. Oral Surgery, Oral Medicine, Oral Pathology, Oral Radiology, and Endodontics, Vol.83, No.1, pp. 72-76, ISSN 1079-2104

de Leeuw R. (2008) Temporomandibular disorders. Guidelines for classification, assessment, and management. 4th ed. Chicago, ISBN 0867154136, Quintessence, USA

Durham, J. (2008) Temporomandibular disorders (TMD): an overview. Oral Surgery, Vol.1, No.2, pp. 60-68, ISSN 1752-2471 
Dworkin, S.F. \& LeResche, L. (1992) Research diagnostic criteria for temporomandibular disorders: Review, criteria, examinations and specifications, critique. Journal of Craniomandibular Disorders : Facial \& Oral Pain, Vol.6, No.4, pp. 301-355, ISSN 08902739

Dylina, T.J. (2001) A common-sence approach to splint therapy. Journal of Prosthetic Dentistry, Vol.86, No.5, pp. 539-545, ISSN 0022-3913

Egermark, I.; Magnusson, T. \& Carlsson, G.E. (2003) A 20-year follow-up of signs and symptoms of temporomandibular disorders and malocclusions in subjects with and without orthodontic treatment in childhood. The Angle Orthodontist, Vo.73, No.2, pp. 109-115, ISSN 0003-3219

Gesch, D.; Bernhardt, O.; Alte, D.; Schwahn, C.; Kocher. T.; John, U. \& Hensel, E. (2004a) Prevalence of signs and symptoms of temporomandibular disorders in an urban and rural German population: results of a population-based Study of Health in Pomerania. Quintessence International, Vol.35, No.2, pp. 143-50, ISSN 0033-6572

Gesch, D.; Bernhardt, O.; Alte, D.; Kocher, T.; John, U. \& Hensel, E. (2004b) Malocclusions and clinical signs or subjective symptoms of temporomandibular disorders (TMD) in adults. Results of the population-based Study of Health in Pomerania (SHIP). Journal of Orofacial Orthopedics, Vol. 65, No.2, pp. 88-103, ISSN 1434-5293

Giannakopoulos, N.N.; Keller, L.; Rammelsberg, P.; Kronmüller, K.-T. \& Schmitter, M. (2010) Anxiety and depression in patients with chronic temporomandibular pain and controls. Jouranl of Dentistry, 2010; Vol.38, No.5, pp. 369-376, ISSN 0300-5712

Green, S.C. (2006) Concepts of TMD Etiology: Effects on Diagnosis and Treatment, In: TMDs. An Evidence-Based Approach to Diagnosis and Treatment, Laskin, D.M.; Green, C.S. \& Hylander, W.L, pp. 219-228, Quintessence, ISBN 0-86715-447-0, Chicago, USA

Gremillion, H.A. (2002) Multidisciplinary diagnosis and management of orofacial pain. General Dentistry, Vol.50, No.2, pp. 178-186, ISSN 0363-6771

Haiter-Neto, F.; Hollender, L.; Barclay, P. \& Maravilla, K.R. (2002) Disk position and the bilaminar zone of the temporomandibular joint in asymptomatic young individuals by magnetic resonance imaging. Oral Surgery, Oral Medicine, Oral Pathology, Oral Radiology, and Endodontics, Vol.94, No.3, pp. 372-8, ISSN 1079-2104

Henrikson, T. \& Nilner, M. (2003) Temporomandibular disorders, occlusion and orthodontic treatment. Journal of Orthodontics, Vol.30, No.2, pp. 129-137, ISSN 1465-3125

Hollins, M.; Harper, D.; Gallagher, S.; Owings, E.W.; Lim, P.F.; Miller, V.; Siddiqi, M.Q. \& Maixner, W. (2009) Perceived intensity and unpleasantness of cutaneous and auditory stimuli: an evaluation of the generalized hypervigilance hypothesis. Pain, Vol.141, No.3, pp. 215-221, ISSN 0304-3959

Huddleston Slater, J.J.; Lobbezoo, F.; Onland-Moret, N.C. \& Naeije, M. (2007) Anterior disc displacement with reduction and symptomatic hypermobility in the human temporomandibular joint: prevalence rates and risk factors in children and teenagers. Journal of Orofacial Pain, Vol.21, No.1, pp.55-62, ISSN 1064-6655

Katzberg, R.W.; Westesson, P.-L.; Tallents, R.H. \& Drake, C.M. (1996) Anatomic Disorders of the Temporomandibular Joint Disc in Asymptomatic Subjects. Journal of Oral and Maxillofacial Surgery, Vol.54, No.2, pp. 147-153, ISSN 0278-2391

Köhler, A.A.; Helkimo, A.N.; Magnusson, T. \& Hugoson, A. (2009) Prevalence of symptoms and signs indicative of temporomandibular disorders in children and adolescents. 
A cross-sectional epidemiological investigation covering two decades. European Archives of Paediatric Dentistry, Vol.10, No. Suppl 1, pp.16-25, ISSN 1818-6300

Kropmans, T.; Dijkstra, P.; Stegenga, B.; Steward, R. \& de Bont, L. (2000) Smallest detectable difference of maximal mouth opening in patients with painfully restricted temporomandibular joint function. European Journal of Oral Sciences, Vol.108, No.1, pp. 9-13, ISSN 0909-8836

Kurita, H.; Uehara, S.; Yokochi, M.; Nakatsuka, A.; Kobayashi, H. \& Kurashina, K. (2006) A long-term follow-up study of radiographically evident degenerative changes in the temporomandibular joint with different conditions of disk displacement. International Journal of Oral and Maxillofacial Surgery, Vol.35, No.1, pp. 49-54, ISSN 0901-5027

Kuttila, M.; Le Bell, Y. \& Alanen, P. (1996) The concepts prevalence, need for treatment, and prevention of temporomandibular disorders: a suggestion for terminology. Acta Odontologica Scandinavica, Vol.54, No.5, pp. 332-336, ISSN 0001-6357

Jensen, U. \& Ruf, S. (2007) Longitudinal changes in temporomandibular disorders in young adults: indication for systematic temporomandibular joint screening. Journal of Orofacial Orthopedics, Vol.68, No.6, pp. 501-509, ISSN 1434-5293

John, M. (1996) Ätiopathogenese von funktionellen Kiefergelenkerkrankungen unter besondere Berücksichtigung der Okklusion. Deutsche zahnärztliche Zeitschrift, Vol.51, No.8, pp. 441-447. ISSN 0012-1029

John, M.; Zwijnenburg, A.; Reiber, Th. \& Haerting, J. (1998) Okklusale Faktoren bei Patienten mit kraniomandibulären Dysfunktionen (CMD) und symptomfreien Probanden. Deutsche zahnärztliche Zeitschrift, Vol.53, No.10, pp. 670-673, ISSN 00121029

Jürgens, J. (2009) Sechs Leitsymptome der Kiefergelenkarthropathie. Deutsche zahnärztliche Zeitschrift, Vol.64, No.5, pp. 308-317, ISSN 0012-1029

Le Bell, Y. \& Kirveskari, P. (1990) Treatment of reciprocal clicking of the temporomandibular joint with a repositioning appliance and occlusal adjustment - results after four and six years. Proceedings of the Finnish Dental Society, Vol.86, No.1, pp. 15-21, PFDSAX

Le Bell, Y.; Jämsä, T.; Korri, S.; Niemi, P.M. \& Alanen, P. (2002) Effect of artificial occlusal inerferences depends on previous experience of temporomandibular disorders. Acta Odontologica Scandinavica, Vol.60, No.4, pp. 219-222, ISSN 0001-6357

LeResche, L., Mancl, L.A.; Drangsholt, M.T.; Saunders, K. \& Korff, M.V. (2005) Relationship of pain and symptoms to pubertal development in adolescents. Pain, Vol.118, No.12, pp. 201-9, ISSN 0304-3959

Luther F. (1998) Orthodontics and the temporomandibular joint: Where are we now? Part 2. Functional occlusion, malocclusion, and TMD. The Angle Orthodontist, Vol.68, No.4, pp. 305-318, ISSN 0003-3219

Lyka, I.; Carlsson, G.E.; Wedel, A. \& Kiliardis, S. (2001) Dentist's perception of risks for molar without anatagonisten. A questionnaire study of dentists in Sweden. Swedish Dental Journal, Vol.25, No.2, pp. 67-73, ISSN 0347-9994

Macfarlane, T.V.; Kenealy, P.; Kingdon, H.A.; Mohlin, B.O.; Pilley, J.R.; Richmond, S. \& Shaw. W.C. (2009) Twenty-year cohort study of health gain from orthodontic treatment: temporomandibular disorders. American Journal of Orthodontics and Dentofacial Orthopedics, Vol.135, No.6, pp. 692.e1-8, ISSN 1097-6752 
Machon, V.; Hirjak, D. \& Lukas, J. (2011) Therapy of the osteoarthritis of the temporomandibular joint. Journal of Cranio-maxillo-facial Surgery. Vol.39, No.2, pp. 127-130, ISSN 1010-5182

Manfredini, D.; Piccotti. F.; Ferronato, G. \& Guarda-Nardini, L. (2010) Age peaks of different RDC/TMD diagnoses in a patient population. Journal of Dentistry, Vo.38, No.5, pp. 392-399, ISSN 0300-5172

Manfredini, D.; Bucci, M.B.; Montagna, F. \& Guarda-Nardini, L. (2011) Temporomandibular disorders assessment: medicolegal considerations in the evidence-based era. Journal of Oral Rehabilitation, Vol.38, No.2, pp. 101-119, ISSN 0305-182X

Michelotti, A. \& Iodice, G. (2010) The role of orthodontics in temporomandibular disorders. Journal of Oral Rehabilitation, Vol.37, No.6; pp. 411-429, ISSN 0305-182X

Moen, K.; Hellem, S.; Geitung, J.T. \& Skartveit, L. (2010) A practical approach to interpretation of MRI of the temporomandibular joint. Acta Radiologica, Vol.51, No.9, pp. 1021-1027, ISSN 0284-1851

Okeson, JP. (2003) Management of Temporomandibular disorders and Occlusion. Mosby, 5th ed., ISBN 0-323-01477-1; St. Louis, USA

Okeson, J.P. \& de Leeuw, R. (2011) Differential diagnosis of temporomandibular disorders and other orofacial pain disorders. Dental Clinics of North America, Vol.55, No.1, pp. 105-120, ISSN 0011-8532

Paesani, D.; Salas, E.; Martinez, A. \& Isberg, A. (1999) Prevalence of temporomandibular joint disk displacement in infants and young children. Oral Surgery, Oral Medicine, Oral Pathology, Oral Radiology, and Endodontics, Vol.87, No1, pp. 15-19, ISSN 10792104

Palla, S. (1998) Myoarthropathien des Kausystems und orofaziale Schmerzen. ZZMK der Universität Zürich, ISBN 3-9521519-0-4, Zürich, Switzerland

Palla, S. (2003) Myoarthropatischer Schmerz: oft verkannt. Der Schmerz, Vol.17, No.6, pp. 425-431, ISSN 0932-433X

Pancherz, H.; Ruf, S. \& Thomalske-Faubert, C. (1999) Mandibular articular disk position changes during Herbst treatment: a prospective longitudinal MRI study. American Journal of Orthodontics and Dentofacial Orthopedics, Vol.116, No.2, pp. 207-214, ISSN 0889-5406

Pellizoni, S.E.; Salioni, M.A.; Juliano, Y.; Guimarães, A.S. \& Alonso, L.G. (2006) Temporomandibular joint disc position and configuration in children with functional unilateral posterior crossbite: a magnetic resonance imaging evaluation. American Journal of Orthodontics and Dentofacial Orthopedics, Vol.129, No.6, pp. 785793, ISSN 0889-5406

Pereira, L.J.; Costa, R.C.; França, J.P.; Pereira, S.M. \& Castelo, P.M. (2009) Risk indicators for signs and symptoms of temporomandibular dysfunction in children. The Journal of Clinical Pediatric Dentistry, Vol.34, No.1, pp. 81-86, ISSN 1053-4628

Petersson A. What you can and cannot see in TMJ imaging - an overview related to the RDC/TMD diagnostic system. (2010) Journal of Oral Rehabilitation, Vol.37, No.10, pp. 771-778, ISSN 0305-182X

von Piekartz H. Physikalische Untersuchung der Dysfunction in der kraniomandibulären Region. In: von Piekartz H (ed). Kiefer, Gesichts- und Zervikalregion. Neuromuskulskeletale Untersuchung, Therapie und Management. Stuttgart-New York: Thieme, 2005:122-66. ISBN: 9783131392312 
Pullinger, A.G.; Seligman, D.A. \& Gornbein, J.A. (1993) A multiple logistic regression analysis of the risk and relative odds of temporomandibular disorders as a function of common occlusal features. Journal of Dental Research, Vol.72, No.6, pp. 968-979, ISSN 0022-0345

Rammelsberg, P.(1998) Untersuchungen über Ätiologie, diagnose und Therapie von Diskopathien des Kiefergelenkes. Quintessenz, ISBN 3-87652-976-X, Berlin, Germany

Schmitter, M.; Essig, M.; Seneadza, V.; Balke, Z.; Schröder, J. \& Rammelsberg, P. (2010) Prevalence of clinical and radiographic signs of osteoarthrosis of the temporomandibular joint in an older persons community. Dento maxillo facial Radiology, Vol.39, No.4, pp. 231-234, ISSN 0250-832X

Shen, Y.H.; Chen, Y.K. \& Chuang, S.Y. (2005) Condylar resorption during active orthodontic treatment and subsequent therapy: report of a special case dealing with iatrogenic TMD possibly related to orthodontic treatment. Journal of Oral Rehabilitation, Vol.32, No.5, pp. 332-336, ISSN 0305-182X

Siegmund, T. \& Harzer, W. (2002) Orthodontic diagnostics and treatment planning in adults with temporomandibular disorders a case report. Journal of Orofacial Orthopedics, Vol.63, No.5, pp. 435-445, ISSN 1434-5293

Slavicek, G. (2009) Okklusion im Schatten Evidenz basierter Medizin. Stomatologie, Vol.106, No.1, pp. 17-22, ISSN 0946-3151

Tecco, S.; Crincoli, V.; Di Bisceglie, B.; Saccucci, M.; Macrĺ, M.; Polimeni, A. \& Festa, F. (2011) Signs and symptoms of temporomandibular joint disorders in Caucasian children and adolescents. Cranio: the Journal of Craniomandibular Practice, Vol.29, No.1, pp. 7179, ISSN 0886-9634

Tecco, S. \& Festa, F. (2010a) Prevalence of signs and symptoms of temporomandibular disorders in children and adolescents with and without crossbites. World Journal of Orthodontics, Vol.11, No.1, pp. 37-42, ISSN 1530-5678

Tecco S, Teté S, Crincoli V, Festa MA, Festa F. (2010b) Fixed orthodontic therapy in temporomandibular disorder (TMD) treatment: an alternative to intraoral splint. Cranio: the Journal of Craniomandibular Practice, Vol.28, No.1, pp. 30-42, ISSN 08869634

Tominaga K, Konoo T, Morimoto Y, Tanaka T, Habu M, Fukuda J. (2007) Changes in temporomandibular disc position during growth in young Japanese. Dento maxillo facial Radiology, Vol.36, No.7, pp. 397-401, ISSN 0250-832X

Toscano, P. \& Defabianis, P. (2009) Clinical evaluation of temporomandibular disorders in children and adolescents: a review of the literature. European Journal of Paediatric Dentistry, Vol.10, No.4, pp. 188-192, ISSN 1591-996X

Tullberg, M.; Tsarapatsani, P.; Huggare, J. \& Kopp S. (2001) Long-term follow-up of early treatment of unilateral forced posterior cross-bite with regard to temporomandibular disorders and associated symptoms. Acta Odontologica Scandinavica, Vol.59, No.5, pp. 280-284, ISSN 0001-6357

Türp, J.C. (2000) Temporomandibular Pain - Clinical Presentation and Impact. Quintessenz, ISBN 3-87652-648-5, Berlin, Germany

Türp, J.C. (2002) Über- Unter- und Fehlversorgung in der Funktionsdiagnostik und therapie - Beispiele, Gefahren, Gründe - Teil I. Schweizer Monatsschrift für Zahnmedizin, Vol.112, No.8, pp. 819-823, ISSN 1011-4203 
Türp, J.C. \& Schindler, H.J. (2003) Zum Zusammnehang zwischen Okklusion und Myoarthropathien. Einführung eines integrierenden neurobiologischen Modells. Schweizer Monatsschrift für Zahnmedizin, Vol.113, No.9, pp. 965-971, ISSN 1011-4203

Wang, J.; Chao, Y.; Wan, Q. \& Zhu, Z. (2008) The possible role of estrogen in the incidence of temporomandibular disorders. Medical Hypotheses, Vol.71, No.4, pp. 564-567, ISSN 0306-9877 


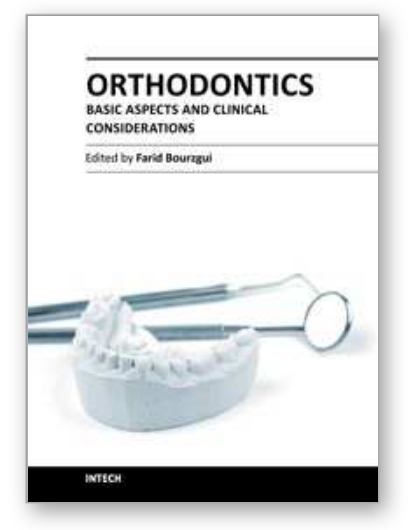

\author{
Orthodontics - Basic Aspects and Clinical Considerations \\ Edited by Prof. Farid Bourzgui
}

ISBN 978-953-51-0143-7

Hard cover, 446 pages

Publisher InTech

Published online 09, March, 2012

Published in print edition March, 2012

The book reflects the ideas of nineteen academic and research experts from different countries. The different sections of this book deal with epidemiological and preventive concepts, a demystification of cranio-mandibular dysfunction, clinical considerations and risk assessment of orthodontic treatment. It provides an overview of the state-of-the-art, outlines the experts' knowledge and their efforts to provide readers with quality content explaining new directions and emerging trends in Orthodontics. The book should be of great value to both orthodontic practitioners and to students in orthodontics, who will find learning resources in connection with their fields of study. This will help them acquire valid knowledge and excellent clinical skills.

\title{
How to reference
}

In order to correctly reference this scholarly work, feel free to copy and paste the following:

Tomislav Badel, Miljenko Marotti and Ivana Savić Pavičin (2012). Temporomandibular Disorders and Orthodontic Treatment - A Review with a Reported Clinical Case, Orthodontics - Basic Aspects and Clinical Considerations, Prof. Farid Bourzgui (Ed.), ISBN: 978-953-51-0143-7, InTech, Available from:

http://www.intechopen.com/books/orthodontics-basic-aspects-and-clinical-considerations/temporomandibulardisorders-and-orthodontic-treatment-a-review-with-reported-clinical-case

\section{INTECH}

open science | open minds

\section{InTech Europe}

University Campus STeP Ri

Slavka Krautzeka 83/A

51000 Rijeka, Croatia

Phone: +385 (51) 770447

Fax: +385 (51) 686166

www.intechopen.com

\section{InTech China}

Unit 405, Office Block, Hotel Equatorial Shanghai

No.65, Yan An Road (West), Shanghai, 200040, China

中国上海市延安西路65号上海国际贵都大饭店办公楼 405 单元

Phone: +86-21-62489820

Fax: +86-21-62489821 
(C) 2012 The Author(s). Licensee IntechOpen. This is an open access article distributed under the terms of the Creative Commons Attribution 3.0 License, which permits unrestricted use, distribution, and reproduction in any medium, provided the original work is properly cited. 